\title{
Pengelolaan Limbah Cair Industri Batik Menggunakan Mikroorganisme di Kecamatan Cluring Kabupaten Banyuwangi
}

Iis Ni'matul Jannah dan Ifa Muhimmatin Universitas 17 Agustus 1945 Banyuwangi iis_jnh@yahoo.com

\begin{abstract}
Abstrak
Saat ini di Banyuwangi khususnya di Kecamatan Cluring banyak bermunculan home industri batik khas Banyuwangi. Selama ini limbah cair batik ditampung dalam bak-bak penampungan dan dibiarkan meresap kedalam tanah tanpa ada proses pengolahan lebih lanjut. Pada penelitian ini penulis meneliti dan mengabdi kepada salah satu home industry yaitu Najiha Batik. Limbah batik yang dihasilkan berasal dari pewarna sintesis yang digunakan oleh pengrajin batik. Maka pada karya tulis ilmiah ini, penulis akan menjelaskan tentang proses pengolahan limbah batik dengan menggunakan mikroorganisme. Sehingga limbah yang dibuang tidak akan membahayakan lingkungan sekitar.
\end{abstract}

Kata Kunci : batik, pengolahan limbah cair, mikroorganisme.

\begin{abstract}
At this time in Banyuwangi especially in Cluring Subdistrict many of the Banyuwangi batik home industries have sprung up. So far, batik liquid waste is collected in reservoirs and allowed to soak into the ground without further processing. In this study the authors examined and served one of the home industries, Najiha Batik. The resulting batik waste comes from synthetic dyes used by batik artisans. So in this scientific paper, the writer will explain about the process of treating batik waste using microorganisms. So that the waste that is disposed of will not endanger the surrounding environment.
\end{abstract}

Keywords : batik, waste water treatment, microorganisms.

\section{PENDAHULUAN}

Batik merupakan salah satu seni budaya yang dimiliki oleh Indonesia dan sejak tahun 2009 telah diakui oleh UNESCO sebagai warisan budaya dunia. Ekspor batik sendiri ditahun 2017 mencapai USD 58,46 juta dengan negara tujuan Jepang, Amerika Serikat dan juga Eropa. ${ }^{1}$ Saat ini di Banyuwangi khususnya di Kecamatan Cluring banyak bermunculan home industri batik khas Banyuwangi. Hal ini memiliki dampak positif terhadap perekonomian pengrajin dan menambah lapangan pekerjaan baru, akan tetapi hal tersebut belum diimbangi dengan kemampuan dan pengetahuan para pengrajin dalam mengelola limbah cair yang dihasilkan dari kegiatan membatik. Para pengrajin batik masih banyak 
yang belum mengetahui cara mengelola limbah cair batik yang dihasilkannya agar sesuai dengan baku mutu lingkungan yang telah ditetapkan oleh pemerintah.

Najiha Batik dipilih sebagai mitra dampingan karena dari hasil wawancara diperoleh informasi bahwa mereka belum memiliki pengetahuan tentang cara pengolahan limbah batik yang mereka hasilkan. Selama ini limbah cair batik ditampung dalam bak-bak penampungan dan dibiarkan meresap kedalam tanah tanpa ada proses pengolahan lebih lanjut. Proses membatik dilakukan melalui beberapa tahap, yaitu tahap persiapan, tahap pemolaan, pemalaman, selanjutnya pewarnaan celup, pelorodan atau penghilangan lilin batik dan yang terakhir adalah finishing. Pada proses membatik dihasilkan limbah yang berwujud gas maupun cairan. Limbah dalam bentuk cair yang dihasilkan oleh industri batik sudah ada mulai tahapan mengolah kain, pewarnaan hingga pelorotan. Pada proses pewarnaan menggunakan bahan pewarna sintetis. Para pengrajin lebih memilih untuk menggunakan pewarna sintesis dibandingkan dengan pewarna alami karena keunggulan yang dimiliki oleh pewarna sintetis, yaitu warna yang dihasilkan dari pewarna sintesis lebih stabil bila dibandingkan dengan menggunakan pewarna alami disamping itu penggunaanya lebih praktis dan lebih mudah mendapatkannya. Sifat pewarna sintesis yang stabil ini menjadi menyebabkan pewarna ini lebih sulit dan lebih lama untuk bisa terurai dilingkungan sehingga dapat menjadi polutan dan menyebabkan gangguan bagi keseimbangan lingkungan perairan. Pada pewarna sintetik didalamnya terkandung senyawa kimia berbahaya yaitu berupa logam berat. Senyawa logam berat yang terdapat pada buangan industri batik cetak, diduga adalah krom $(\mathrm{Cr})$, Timbal $(\mathrm{Pb})$, Nikel $(\mathrm{Ni})$, tembaga $(\mathrm{Cu})$, dan mangan (Mn). Senyawa logam berat dapat menyebabkan kanker pada mahluk hidup. Limbah cair batik selain mengandung senyawa berbahaya juga dapat meningkatkan COD (Chemical Oxygen Demand) dan BOD (Biological Oxygen Demand) air sehingga dapat mengganggu ekosistem perairan. ${ }^{2}$

Berdasarkan analisis situasi yang telah dijelaskan maka mitra kami memiliki permasalahan berupa belum dimilikinya pengetahuan dan ketrampilan dalam mengelola limbah cair yang dihasilkan dari industri batik dan limbah yang dihasilkan dari proses membatik masih berpotensi mencemari lingkungan karena belum melalui proses pengolahan yang tepat terlebih dahulu sebelum dibuang kelingkungan. Menurut Peraturan Menteri Lingkungan Hidup Nomor 5 Tahun 2014 tentang baku mutu air limbah tekstil menyebutkan bahwa untuk parameter BOD kadar paling tinggi yang diperbolehkan adalah sebesar $60 \mathrm{mg} / \mathrm{L}$, kadar COD (Chemical Oxygen Demand) sebesar $150 \mathrm{mg} / \mathrm{l}$, TSS (total suspended solids) $50 \mathrm{mg} / \mathrm{L}$,

1 "Batik", (2006), Yayasan Harapan Kita, TMII, Jakarta

2 Sugiyana, D. Pencemaran Logam Berat pada Limbah Industri Tekstil dan Alternatif Material Penyerap Ekonomis (Bandung:Balai Besar Tekstil, 2003) 
Fenol total 0,5 mg/L, Crom (Cr) total 1,0 mg/L, Amonia total 8,0 mg/L, Sulfida 0,3 mg/L, minyak dan lemak 3,0 mg/L, pH 6,0-9,0, serta debit limbah paling tinggi $100 \mathrm{~m}^{3} /$ ton produk tekstil. ${ }^{3}$

Guna memenuhi baku mutu yang telah ditetapkan maka beberapa cara dapat dilakukan untuk mengolah limbah cair batik. Pengolahan dapat dilakukan baik secara kimia, fisika maupun secara biologis. Pengolahan secara biologis dapat dilakukan secara aerob dan anaerob. Secara Biologis pengolahan limbah dapat dilakukan dengan menggunakan lumpur aktif karena dapat mendegradasi limbah secara lebih efektif dan ekonomis. ${ }^{4}$ Pengolahan dengan lumpur aktif memanfaatkan bakteri indigenous (bakteri proteolitik dan selulolitik) yang memiliki kemampuan mempercepat degradasi senyawa organik. ${ }^{5}$ Pengolahan dengan lumpur aktif secara aerob dapat menurunkan kadar COD hingga 76,59\% sedangkan pada kondisi anaerob sebesar 69,43\% dengan masa tinggal sel 6 jam dan 6 hari. ${ }^{6}$ Berdasarkan permasalahan yang dihadapi oleh mitra maka solusi yang dapat ditawarkan adalah dengan cara memberikan pelatihan atau edukasi cara pengelolaan limbah cair batik dengan metode lumpur aktif (active sludge) yaitu cara pengolahan limbah cair batik secara biologis dengan menggunakan mikroorganisme indigenous yang dijalankan secara aerob.

\section{METODE PELAKSANAAN}

Pendampingan pengolahan limbah cair batik ini mengambil tempat di Najiha Batik yang beralamatkan di Dusun Simbar Desa Tampo Kecamatan Cluring Banyuwangi selama 2 bulan mulai bulan Maret - Mei 2019. Strategi yang digunakan dalam pengabdian ini adalah dengan memberikan pelatihan atau edukasi tentang cara pengolahan limbah cair yang dihasilkan oleh industri batik dengan menggunakan mikroorganisme dengan metode lumpur aktif. Pihak yang terlibat dalam pengabdian ini adalah pemilik usaha Najiha Batik yang mengambil peran sebagai pelaksana dalam kegiatan ini. Adapun langkah yang dilakukan dalam pengabdian ini adalah: a. memberikan penjelasan kepada pemilik usaha/mitra tentang bahaya-bahaya yang bisa ditimbulkan dari limbah cair batik yang tidak dikelola dengan baik dan benar, b. memberikan penjelasan dan

3 “Peraturan Menteri Lingkungan Hidup Republik Indonesia Nomor 5 Tahun 2014 tentang Baku Mutu Air Limbah", online:〈www.pelatihanlingkungan.com〉

${ }^{4}$ Eskani, dkk. "Efektivitas Pengolahan Air Limbah Batik dengan cara Kimia dan Biologi" (2005) 22:16-27 Dinamika Kerajinan dan Batik, (Online), 〈http://ejournal.kemenperin.go.id〉

5 Sunarti, T.C, Suprihatin \& Lauda R.D. "Stabilisasi Sludge dari Instalasi Pengolahan Air Limbah (IPAL) Menggunakan Starter Bakteri Indigenous pada Aerobic Sludge Digester” (2014), 3 (2). (online), 〈http://journal.ipb.ac.id/index.php/e-jaii/article/view/9198/7235〉, diakses tanggal 12 Mei 2019.

${ }^{6}$ Sianita, D \& Nurchayati, I.S, "Kajian pengolahan limbah cair industri batik, kombinasi aerob - anaerob dan penggunaan koagulan tawas"(2009),(online), 〈http://eprints.undip.ac.id/3183/1/Presentation_MakalahQ_New.pdf〉 
pemahaman tentang baku mutu lingkungan yang telah ditetapkan oleh pemerintah terkait dengan limbah cair tekstil, c. menjelaskan kepada pemilik usaha/mitra tentang tata cara pengolahan limbah cair batik dengan metode lumpur aktif, d. pemilik usaha/mitra menerapkan/mempraktekkan pengolahan limbah cair batik secara langsung, e. evaluasi, dilakukan untuk mengetahui sejauh mana program telah dijalankan sesuai dengan rencana.

Pada pelaksanaan/penerapan pengolahan limbah cair batik dengan metode lumpur aktif yang perlu disiapkan adalah pertama, menyiapkan alat dan bahan yang digunakan yang meliputi bak plastik, gelas ukur, cetok, termometer, timbangan, pengaduk yang berupa motor filter aquarium (waterpump), dan DO meter. Bahan yang digunakan meliputi pupuk NPK, limbah cair batik, tawas, kertas $\mathrm{pH}$ indikator universal, mikroorganisme yang berasal dari lumpur sungai dan selokan pembuangan limbah batik. Kedua, menyiapkan seeding. Seeding dibuat dengan mencampurkan 2,5 liter air dengan 7,5 liter air lumpur selokan pembuangan limbah cair batik serta lumpur sungai. Selanjutnya campuran tersebut diaerasi selama $3 \times 24$ jam. Ketiga, melakukan aklimasi, aklimasi dilakukan dengan mencampur seeding yang sudah dibuat sebelumnya dengan limbah yang sudah disaring dan dikoagulasi dengan tawas dengan perbandingan 1:40. Kemudian campuran tersebut diaerasi selama 2 × 24 jam. Hasilnya disebut dengan lumpur aktif. Kelima, melakukan pengolahan limbah cair batik secara aerob dengan menggunakan lumpur aktif yang telah dibuat sebelumnya. Adapun skema pengolahan limbah dengan metode lumpur aktif dapat dilihat pada Gambar 1.

Gambar l. Skema pengolahan limbah cair dengan metode lumpur aktif ${ }^{7}$

\section{HASIL DAN PEMBAHASAN}

\section{A. Analisis Limbah Cair Batik Sebelum Pengolahan dengan Mikroorganisme}

Sebelum dilakukan pengolahan limbah cair batik dengan menggunakan mikroorganisme (metode lumpur aktif) maka limbah cair batik dianalisa dengan berdasarkan parameter: warna, alkalinitas $(\mathrm{pH})$, suhu, dan DO. Hasil analisa setiap parameter dapat dilihat pada Tabel 1 dan Gambar 2.

${ }^{7}$ Eskani, dkk, supra note 5 
Gambar 2. Analisis limbah cair batik sebelum pengolahan dengan mikroorganisme

Program pengabdian yang dilaksanakan di Najiha Batik bertujuan untuk memberikan edukasi kepada pemilik usaha batik dalam menangani limbah cair yang dihasilkan dari proses pembatikan. Jenis limbah yang dihasilkan oleh Najiha Batik sebagian besar berupa limbah cair. Pada akhir proses pembatikan, limbah yang dihasilkan langsung dialirkan kedalam kolam-kolam penampungan dibiarkan tanpa ada proses pengolahan limbah lebih lanjut. Hal ini tentunya dapat mencemari sumber air tanah karena kolam-kolam penampungannya tersebut tidak diplester sehingga memungkinkan senyawa-senyawa kimia yang ada dalam air limbah dapat masuk meresap kedalam tanah. Proses pengolahan limbah diawali dengan menganalisis kualitas air limbah batik yang diperoleh dari bak-bak penampungan pada beberapa parameter seperti warna, $\mathrm{pH}$, suhu dan DO. Berdasarkan hasil pengukuran diperoleh nilai derajat keasaman $(\mathrm{pH})$ limbah cair batik berkisar 11 artinya memiliki $\mathrm{pH}$ basa. Warna limbah cair batik berwarna biru kehitaman dan DO air limbah sekitar 8,6 mg/L.

Berdasarkan hasil wawancara dengan pemilik usaha Najiha batik, bahan yang digunakan dalam proses pembatikan terdiri atas pewarna Remazol dan water glass (natrium silikat). Pewarna Remazol memiliki struktur kimia terdiri atas gugus kromofor Azo, yaitu gugus yang terdiri atas kromofor yang terlokalisasi dengan ikatan rangkap terkonjugasi dan mengandung heteroatom (biasanya, N, O dan S) dengan elektron non ikatan. ${ }^{8}$ Pewarna Remazol juga bersifat stabil, larut dalam air, mempunyai ketahanan luntur yang baik, serta daya afinitasnya rendah. Pewarna Remazol tergolong dalam pewarna reaktif yang dapat berikatan dengan serat kain secara langsung. ${ }^{9}$ Bahan lain yang digunakan dalam proses pembatikan adalah waterglass, berfungsi untuk mengikat/memfiksasi warna sehingga warna tidak luntur. Water glass atau Natrium silikat memiliki sifat dapat larut dalam air dan menghasilkan larutan yang bersifat alkali.

\section{B. Pembuatan Seeding}

Tahap yang dilakukan setelah pengukuran parameter air limbah adalah pembuatan seeding. Pembuatan seeding dilakukan dengan cara mencampur lumpur

\footnotetext{
${ }^{8}$ Hidayat, Asep \& Siregar, C.A.Telaah Mendalam tentang Bioremidiasi:Teori dan aplikasinya dalam upaya konservasi tanah dan air (Bogor: IPBPress, 2017)

${ }^{9}$ Daranindra. Perencanaan alat bantu Proses Pencelupan Zat Warna dan Penguncian Warna Pada Kain Bantik sebagai Usaha Mengurangi Interaksi dengan Zat Kimia dan Memperbaiki Postur Kerja (Studi Kasus: Batik Brotoseno Masaran, Sragen)(Program Studi Teknik Industri Fakultas Teknik, Universitas Sebelas Maret, 2010).
} 
yang berasal dari selokan yang ada disekitar bak penampungan limbah cair batik dengan lumpur yang berasal dari sungai. Dalam lumpur selokan limbah batik terdapat mikroorganisme indigenous, yaitu mikroorganisme yang berasal dari habitatnya sendiri dengan kondisi lingkungan sesuai dengan kebutuhan hidupnya sehingga mikroorganisme dapat tumbuh dan berkembang biak memperbanyak diri dan tidak membutuhkan adaptasi dengan lingkungannya. Jenis mikrobia yang biasa terdapat di dalam limbah cair batik yaitu dari Genus Bacillus dan Pseudomonas. ${ }^{10}$ Pada lumpur sungai juga terdapat berbagai macam mikroorganisme aerobik yang sangat berguna dalam pemurnian alami di sungai. Dalam hal ini baik mikroorganisme indigenous yang ada dalam lumpur selokan limbah batik dan lumpur sungai dimanfaatkan potensinya untuk mendegradasi zat organik yang ada dalam limbah cair batik.

\section{Aklimasi}

Aklimasi merupakan penyesuaian mikroorganisme (seeding) yang telah dibuat dengan lingkungan/limbah cair batik. Tahap ini dilakukan dengan cara mencampur seeding dengan limbah cair. Hal ini dilakukan guna mempersiapkan mikroorganisme agar dapat beradaptasi dengan substrat/limbah cair batik sehingga siap untuk digunakan mendegradasi limbah cair batik.

\section{Pengolahan Limbah Cair Batik menggunakan Mikroorganisme}

Pengolahan limbah cair batik dilakukan melalui 3 proses utama yaitu (1) proses fisik, dilakukan dengan cara mengendapan dan menyaring padatan kasar yang tersuspensi dalam air limbah cair batik, (2) proses kimiawi, proses ini dilakukan dengan menggunakan metode koagulasi dan flokulasi air limbah batik dengan tujuan untuk pengaturan $\mathrm{pH}$ air limbah dan memudahkan proses pengendapan padatan yang terlarut dalam air limbah dengan membentuk flok, (3) proses biologis yang dilakukan dengan metode lumpur aktif dengan tujuan untuk mengurangi komponen organik terlarut melalui pendegradasian yang dilakukan oleh mikroorganisme indigenous. Sebelum dilakukan pengolahan, air limbah sebelumnya disaring untuk menghilangkan material kasar yang terapung atau terlarut dalam air limbah. Selanjutnya limbah cair dikoagulasi dengan menggunakan $\mathrm{Al}_{2}\left(\mathrm{SO}_{4}\right)_{3}$. Setelah dikoagulasi limbah di cek $\mathrm{pH}$ nya agar sesuai dengan $\mathrm{pH}$ untuk pertumbuhan mikroorganisme yaitu kisaran 6-7 selanjutnya dimasukkan/dialirkan ke dalam bak aerasi dan ditambahkan dengan kultur/lumpur aktif dengan perbandingan 80\% limbah dan 20\% kultur aktif.

${ }^{10}$ Mayla, dkk." Pemanfaatan Bakteri Indigenus pada Remediasi Limbah Cair Batik Pewarnaan Remazol Hitam dengan Medium Lumpur Aktif",(2017), online:<http://e-journal.uajy.ac.id/11894/1/JURNAL.pdf 
Selanjutnya ditambahkan dengan pupuk NPK kedalam bak sebagai sumber nutrisi bagi mikroorganisme. Pengolahan limbah cair dijalankan secara aerob (menggunakan $\mathrm{O}_{2}$ ) sehingga dibutuhkan aerator/waterpump selama pengolahan limbah. Waterpump berfungsi untuk mengaduk nutrisi dan menyediakan asupan oksigen sehingga dapat tersebar merata kesegala arah dalam bak aerasi sehingga mikroorganisme aerob yang hidup dalam air limbah mendapat cukup nutrisi dan oksigen dan mampu mendegradasi limbah dengan maksimal. Proses ini dilakukan selama 5 hari pada kisaran suhu $30^{\circ} \mathrm{C}$ dan pH 6-8 serta dilakukan pengadukan secara kontinyu. Hasil dari tahapan ini dapat dilihat pada Tabel 2 dan Gambar 3.

Tabel 2. Analisa limbah cair batik setelah pengolahan dengan mikroorganisme indigenous

\begin{tabular}{cc}
\hline Parameter & Hasil Analisa \\
\hline Warna & Kuning terang \\
\hline Ph & 7 \\
\hline Suhu & $28,6^{\circ} \mathrm{C}$ \\
\hline DO & $7,6 \mathrm{mg} / \mathrm{L}$
\end{tabular}

Pengolahan limbah dengan menerapkan prinsip pengolahan biologis (menggunakan lumpur akktif) dijalankan secara aerob. Prinsip ini memanfaatkan kemampuan mikroorganisme aerob yang terdapat dalam lumpur dalam menguraikan senyawa organik terlarut. Limbah cair batik terkandung senyawa organik berupa kanji, sisa lilin, abu soda yang bersal dari proses pelorotan. Pada proses pengolahan dengan menggunakan mikroorganisme secara aerob terjadi reaksi sebagai berikut:

Bahan organik + mikroorganisme $+\mathrm{O}_{2} \rightarrow$ biomassa $+\mathrm{CO}_{2}+\mathrm{H}_{2} \mathrm{O}$

Pada proses pengolahan juga ditambahkan dengan pupuk NPK sebagai tambahan nutrisi bagi mikroorganisme. Pengolahan dilakukan dalam bak aerator yang dilengkapi dengan waterpump yang berfungsi selain untuk memberikan asupan udara juga bertujuan untuk mengaduk campuran sehingga nutrisi yang ditambahkan berupa pupuk NPK dapat tercampur merata dan semua mikroorganisme yang ada didalam bak mendapatkan nutrisi dan oksigen. Awal pengolahan limbah dilakukan dengan menyaring limbah cair untuk menghilangkan partikel kasar serta menambahkan tawas yang berfungsi untuk mengendapkan dan menurunkan $\mathrm{pH}$ limbah hingga $\mathrm{pH}$ netral. Langkah selanjutnya adalah mengalirkan pada bak kedua yaitu bak aerator yang kedalamnya ditambahkan dengan pupuk NPK dan dan gula sebagai sumber nutrisi bagi mikroorganisme selanjutnya diaerasi selama kurang lebih 5 hari. Langkah selanjutnya adalah mengalirkan pada bak ketiga yaitu bak pengendapan. Air limbah yang ada dipermukaan dikeluarkan dan sebagian lumpurnya 
dikembalikan lagi kedalam bak pertama.

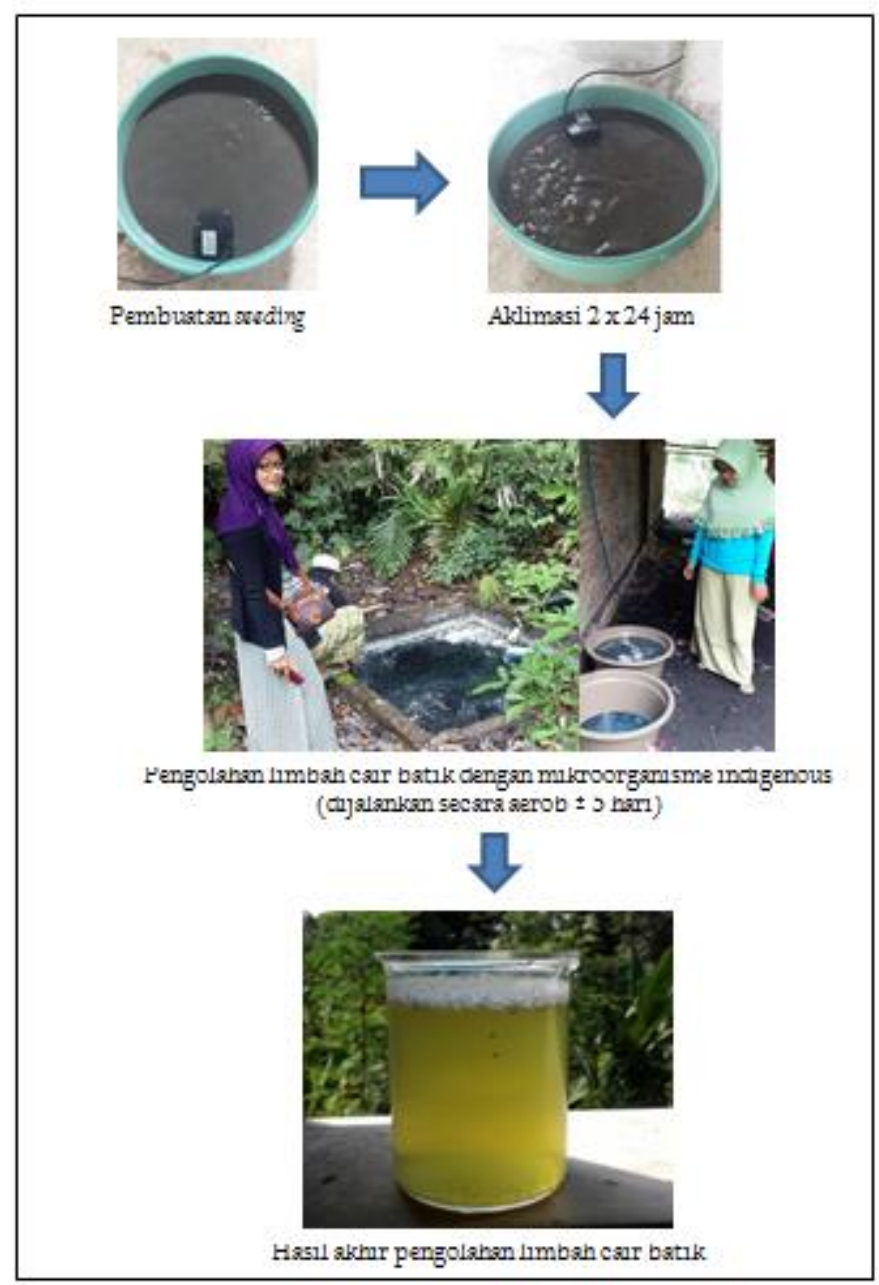

Gambar 3. Proses pengolahan limbah cair batik dengan mikroorganisme

Hasilnya setelah dilakukan pengolahan limbah dengan menggunakan mikroorganisme indigenous dengan metode lumpur aktif, terjadi penurunan baik pada pH (menjadi 7), DO (7,6 mg/L), serta warna limbah (berwarna lebih cerah). Hal ini disebabkan oleh kemampuan mikroorganisme dalam mendegradasi limbah cair. Bakteri indigenous memiliki kemampuan yang tinggi dalam mendegradasi senyawa organik dan mampu menghasilkan perbandingan $\mathrm{C} / \mathrm{N}$ yang tinggi. Dalam bak aerasi mikroorganisme aerob menghodrolisa senyawa organik yang terdapat dalam air limbah dengan menggunakan enzim hidrolitik selanjutnya mengoksidasi senyawa organik tersebut menjadi $\mathrm{H}_{2} \mathrm{O}$ dan $\mathrm{CO}_{2} .^{11}$ Reakasi hidrolisa/penguraian terjadi melalui reaksi enzimatis dengan

${ }^{11}$ Eskani, dkk.supra note 5 
melibatkan enzim yang terdapat dalam mikroorganisme yang mengkatalisis terjadinya reaksi oksidasi-reduksi. Setiap mikroba potensial memiliki kemampuan yang berbeda-beda dalam proses penguraian. Mikroba secara sempurna akan memanfaatkan molekul zat pewarna sebaga sumber karbon, nitrogen dan energi sehingga penurunan konsentrasi polutan terjadi dalam makna yang sesungguhnya. ${ }^{12}$

\section{E. Evaluasi}

Berdasarkan metode yang telah dilaksanakan maka beberapa hal yang masih menjadi kendala adalah penggunaan listrik yang besar untuk menjalankan aerator karena sistem harus dijalankan selama 7 hari dan senantiasa dipantau sehingga membutuhkan bantuan dari pihak-pihak terkait guna kelancaran proses pengolahan limbah cair batik.

\section{PENUTUP}

Berdasarkan hasil kegiatan pengabdian dan pendampingan yang telah dilakukan di IKM Najiha Batik, mitra telah mendapatkan edukasi tentang cara pengolahan limbah cair batik dengan memanfaatkan mikroorganisme indigenous (metode lumpur aktif) yang dijalankan secara aerob. Metode ini diambil karena mempertimbangkan beberapa hal diantaranya bahan yang digunakan untuk membuat lumpur aktif berupa lumpur sungai dan lumpur dari selokan pembuangan limbah mudah didapat sehingga lebih ekonomis akan tetapi metode ini juga membutuhkan daya listrik yang terus-menerus karena digunakan untuk proses aerasi sistem lumpur aktif.

Berbekal dari edukasi yang telah dilakukan dalam program pengabdian, hendaknya mitra segera membuat instalasi pengolahan air limbah sendiri dengan memanfaatkan mikroorganisme indigenous dalam skala lebih besar guna menampung air limbah yang secara kontinyu dihasilkan.

\section{Ucapan Terima Kasih}

Terima kasih kepada Pusat Penelitian dan Pengabdian Masyarakat Universitas 17 Agustus 1945 Banyuwangi atas dukungan dana untuk menunjang keterlaksanaan program pengabdian ini.

${ }^{12}$ Hidayat, Asep \& Siregar, C.A. supra note 9 


\section{DAFTAR PUSTAKA}

"Batik", (2006), Yayasan Harapan Kita, TMII, Jakarta

"Peraturan Menteri Lingkungan Hidup Republik Indonesia Nomor 5 Tahun 2014 tentang Baku Mutu Air Limbah", online:〈www.pelatihanlingkungan.com>

Daranindra. Perencanaan alat bantu Proses Pencelupan Zat Warna dan Penguncian Warna Pada Kain Bantik sebagai Usaha Mengurangi Interaksi dengan Zat Kimia dan Memperbaiki Postur Kerja (Studi Kasus: Batik Brotoseno Masaran, Sragen)(Program Studi Teknik Industri Fakultas Teknik, Universitas Sebelas Maret, 2010).

Eskani, dkk, supra note 5

Eskani, dkk. "Efektivitas Pengolahan Air Limbah Batik dengan cara Kimia dan Biologi" (2005) 22:16-27 Dinamika Kerajinan dan Batik, (Online), 〈http://ejournal.kemenperin.go.id〉

Eskani, dkk.supra note 5

Hidayat, Asep \& Siregar, C.A. supra note 9

Hidayat, Asep \& Siregar, C.A.Telaah Mendalam tentang Bioremidiasi:Teori dan aplikasinya dalam upaya konservasi tanah dan air (Bogor: IPBPress, 2017)

Mayla, dkk." Pemanfaatan Bakteri Indigenus pada Remediasi Limbah Cair Batik Pewarnaan Remazol Hitam dengan Medium Lumpur Aktif",(2017), online:/http://e-journal.uajy.ac.id/11894/1/JURNAL.pdf

Sianita, D \& Nurchayati, I.S, "Kajian pengolahan limbah cair industri batik, kombinasi aerob - anaerob dan penggunaan koagulan tawas"(2009),(online), 〈http://eprints.undip.ac.id/3183/1/Presentation_MakalahQ_New.pdf〉

Sugiyana, D. Pencemaran Logam Berat pada Limbah Industri Tekstil dan Alternatif Material Penyerap Ekonomis (Bandung:Balai Besar Tekstil, 2003)

Sunarti, T.C, Suprihatin \& Lauda R.D. "Stabilisasi Sludge dari Instalasi Pengolahan Air Limbah (IPAL) Menggunakan Starter Bakteri Indigenous pada Aerobic Sludge Digester" (2014), 3 (2). (online), 〈http://journal.ipb.ac.id/index.php/e-jaii/article/view/9198/7235〉, diakses tanggal 12 Mei 2019. 